\title{
"That's Not Fair!" Children's Judgments of Maternal Fairness and Good/Bad Intentions
}

\author{
Marla Johnston \\ SUNY at Farmingdale State College \\ Herbert D. Saltzstein \\ The Graduate School and University Center of the City University of New York
}

\begin{abstract}
Do children use their own moral judgments as a template against which to judge a parent's fairness, and does that depend on the child's age? Piaget's concept of objective-to-subjective responsibility (a focus on outcome to a focus on intentions) was the template for the current study. The research question was how do children of different ages evaluate the fairness of mothers' praise/blame for acts featuring different combinations of good/bad intentions and outcome. Forty-eight children (ages 3-11 years) heard two stories in which the outcome did not match the intentions. There were two versions of each story type: In one, the mother praised the child in the story; in the other, she blamed the child. Findings were that (a) children under 7 judged mothers who praised as fair and mothers who blamed as unfair regardless of the intentionality of the act, whereas (b) children 7 and older judged fairness based on consistency of mother's reaction with the child protagonist's intentions, thus using moral intentionality as a template to evaluate fairness.
\end{abstract}

Keywords: maternal fairness, moral development, Piaget

\section{Introduction}

"That's not fair!" It's a phrase that children typically use at a young age. They shout it with incredulity at any infraction they judge to be unfair, but by what rules do they decide something is fair or unfair? And, do these rules change with age? It seems reasonable that the concept of fairness would be closely intertwined with other concepts in the moral domain. The present study is an investigation of how children's implicit rules for judging whether a parent is fair or unfair evolve along with the development of their own moral judgments. More specifically, this study explored whether children use the match between their parent's discipline and their own moral judgments to judge fairness, and whether this implicit rule changes with age.

The hypotheses proposed here are based on Piaget's claim that moral intentionality develops gradually and depends on general social and cognitive development. According to Piaget, it is only by middle childhood that children adhere to Kant's (1785/1958) dictum that the only truly good (in the moral sense) thing is a good will or, in more modern terms, a good intention. Before middle childhood, attention is captured by or centers on the outcome of the act, particularly the physical outcome, whether in the form of physical damage or adult disapproval and punishment. This finding has been the stimulus for considerable research, either confirming it as a genuine developmental shift or as an artifact of the particular experimental method employed (e.g., Costanzo, Coie, Grumet, \& Farnill, 1973; Nobes, Panagiotaki, \& Pawson, 2009; Suls, Gutkin, \& Kalle, 1979). Additionally, 
Smetana (1999) has discussed how socialization that takes place in domain-specific parent/child interactions may facilitate children's moral understanding. A child's moral reasoning is believed to be affected by both affective and cognitive aspects of the parent-child interaction. Killen and Smetana (2015) generally conclude that "morality is revealed by the individual's evaluation and interpretation of social events (rather than from direct teaching or transmission)" (p. 706). It can be concluded that, while clearly sensitive to performance factors involving semantic understanding, memory, interpretation of the task, etc., a shift in moral comprehension becomes well ensconced possibly only after the child's other cognitive capacities, particularly perspective-taking (e.g., Stone \& Selman, 1982), develop.

Thus, rather than refighting the previous battles about the nuances of the developmental shift to moral intentionality, it is proposed to test whether it makes any difference in the child's interpretation of parental fairness. The essence of this study is to present to children of different ages what one might term preintentional and intentional vignettes in which the parent praises or scolds the child, for well-intended or bad-intended acts, and see whether the child judges the parent as fair or unfair. In other words, do older, but not younger, children judge parental praise/blame according to whether it matches the child actor's intentions? Thus, what makes the current research study different from studies in the past is that this research also specifically examines how the child's own moral judgments serve as a template against which he or she evaluates an adult's intervention as fair/unfair.

As Grusec and Goodnow (1994) have argued, to understand how parental discipline and other interventions affect children's development, it is necessary to gain access to their understanding and evaluation of the discipline or intervention. That is, they argue plausibly that the effect of what a parent does is not invariant, but depends on the child's interpretation of that parental intervention, specifically as to its fairness. It is this concept of what is fair that the current study explores developmentally, using the shift to an emphasis on intentionality.

Although they did not examine the concept of fairness directly, Jambon and Smetana (2014) explored how varying transgressions are viewed as more deserving of punishment and how children are able to increasingly coordinate differing factors related to such moral evaluations as a function of their age. Smetana, Jambon, and Ball (2014) have also pointed out how emotional appraisals are commingled with moral reasoning from a social domain perspective and this may also play a role in children's moral and fairness evaluations of maternal reactions to transgressions.

Of course, it should be noted that other researchers have studied children's judgments of some aspects of fairness (e.g., Castelli, Massaro, Sanfey, \& Marchetti, 2014; Gummerum \& Chu, 2014; Konstantareas \& Debois, 2001; LoBue, Nishida, Chiong, DeLoache, \& Haidt, 2011; Shaw, DeScioli, \& Olson, 2012).Despite reporting interesting findings, none has examined the children's judgments of the fairness of parent discipline in relation to the child's intentionality and the outcome of the act. Konstantareas and Debois (2001) did explore preschoolers' judgments of five types of maternal discipline that were considered to be psychological maltreatment (excessive withdrawal of privileges, differential sibling treatment, public humiliation, etc.). Their findings indicate that preschoolers differentiate the fairness/unfairness of discipline practices, although the vignettes used did not have the children judge the act that lead to the discipline in question. Thus, the current study is quite different from Konstantareas and Debois (2001), because the current study explored children's judgments of maternal fairness as a function of whether the maternal reaction was perceived as a "just" response to a transgression, rather than the fairness of the discipline method itself. Overall, 
given the relative scarcity of research exploring fairness with act intentionality, it was the purpose of the present study to begin examining how maternal discipline is judged fair or unfair according to its match to the child's intentions and how this varies with the age of the child.

To recapitulate, the present study was designed to help answer the following question: Do children judge a mother's reaction to a transgression differently depending on simply whether that mother's judgment is positive or negative or by whether the mother's reaction matches the intentions behind the child's act? More specifically, do children judge what is a fair parental reaction to a transgression based simply on the omnipotent power of an adult, regardless of transgression, or according to the consistency between the parental response and the fictive child's intentions, what might be called the "intentionality criterion," that is, the consistency between the child's intention and corresponding parental approval or reprimand? And, does the answer depend on the age of the child?

\section{Method}

\section{Participants}

The participants consisted of 48 children from various public and private schools located in a suburb of New York City, New York. The children were primarily from middle-class or upper-middle-class socioeconomic backgrounds. The children ranged in age from 3 to 11 years and were divided into two groups, those below 7 years, 0 months and those above. This age division was based on Piaget's approximate ages for heteronomous and autonomous moral reasoning. Although there was concern expressed over the delineation in older versus younger age groups, Bearison and Isaccs (1975) have found that while 6-year-olds may be capable of examining intentionality when making moral judgments, they appear to not spontaneously do so unless it is suggested by others. The two groups consisted of 25 younger participants (14 girls; 11 boys) and 23 older participants (15 girls; eight boys).

\section{Procedure}

After obtaining Institutional Review Board approval from The Graduate School and University Center of the City University of New York (Approval \#09-10-1843), parental consent, and subsequent verbal assent from the child participants, the researcher met with each child individually either in their home or local library. The researcher introduced herself to the child and explained that she had some stories and she was trying to find out what children thought of them. Each child was first read a warm-up story to ensure that they understood the procedure, as well as the concepts of good/bad and fair/unfair. In the warm-up story, the protagonist purposely committed a bad intended act that had a good outcome. The mother in the story reacted negatively to the child committing the illintended act by reprimanding that child for doing a bad thing and having the child sit in "time out." At the end of the story, each child was asked if the protagonist in the story did something good or bad and if the mother was fair or not fair and why. The children rated how good or bad the protagonist was by pointing to a face on a 5 -point scale marked with smiley/frown faces. The children were also asked to indicate level of fairness of the mother on the same type of scale. The scale consisted of five faces with the middle face being neutral and the uppermost face smiling and the lowermost face frowning. The meaning of the faces was explained to each child prior to the stories to make sure he/she understood their meaning. Previous studies, as noted above (e.g., Konstantareas \& Debois, 2001; LoBue et al., 2011), have shown that even young preschoolers have an understanding 
of fairness and all the participants in this study easily understood the scale, the concepts of good/bad and fair/unfair, as well as the warm-up story.

\section{Measures}

The stories varied in that some variants featured a positive maternal reaction (approval and praise) to the transgression in the story, while others featured a negative maternal reaction (disapproval and blame). Thus, the four stories featured (a) good intention, bad outcome, followed by a positive maternal reaction (GI/BO/+); (b) good intention, bad outcome, followed by a negative maternal reaction (GI/BO/-); (c) bad intention, good outcome, followed by positive maternal reaction (BI/GO/+); and (d) bad intention, good outcome, followed by a negative maternal reaction (BI/GO/-). The good intention/bad outcome stories were identical except for the mother's reaction at the end, and so were the bad intention/good outcome stories. All stories had male and female versions administered so as to match the gender of the individual child participant.

In the good intention/bad outcome stories, the protagonist is an older sibling who wants to help a younger sibling go down a large slide. The older sibling is trying to do something nice by helping the younger child go down the slide only the younger child accidentally falls off the slide in the process. In the positive maternal reaction version of this story, the mother returns to the children, comforts the younger child, and thanks the older one for trying to do something nice. In the negative maternal reaction version, the mother scolds the older child for allowing this to happen and sends the older child to their room for a time out. In the bad intention/good outcome stories, the protagonist in the story is a child who is angry with a friend because the friend does not want to play the games the protagonist wants to play. In anger, the protagonist decides to push the friend into a giant mud puddle by the street. In doing so, the protagonist inadvertently saves the friend from running into the street and being hit by a car. In the positive maternal reaction version of this story, the mother runs to the children and thanks the protagonist for saving the friend. In the negative maternal reaction version, the mother says she's glad the friend is alright, but she explains that while she witnessed the protagonist's true intentions and sends the protagonist to his/her room for a time out.

Each child in the study was read one good intention story and one bad intention and there was story counterbalancing for story type. The positive or negative ending was randomly assigned and as such, while all children were sure to hear both bad and good-intended stories, the combination of stories was not equally distributed (as indicated in the results below). After each story, the participant was asked if the child in the story did something good or bad, and they indicated how good or bad it was by pointing to a face on the smile face 7-point scale. Participants were also asked whether the mother in the story was fair or not, and how fair/unfair she was by indicating that on the smile face scale, as well. The children's responses were voice recorded during this session to enable us to disambiguate any unclear reasoning, which was found to be unnecessary.

\section{Results}

The data were analyzed to address two specific questions: (a) What is the relationship between a child's age and their use of intentions as a significant factor in making moral judgments, and (b) do older, but not younger, children use the match between the actor's intentionality and the fictive mothers' reaction as the rule for fairness of mother? Regarding the latter, it was anticipated that the older children (those 7 or older) would judge the mother as fair when her reaction (approval/disapproval) matched the story actor's intentions, regardless of the story outcome. Further, 
younger children would judge the mother as fair when she approved the story child and unfair when she disapproved of the story child regardless of the fictive child's intentions.

For cross-tab analyses where the size of the sample was adequate, we used chi-square, and where the size was less than adequate, we used Fisher's exact test. Chi-square analyses were performed to evaluate whether older and younger children differed in their judgments of whether the mother was fair or not fair based on whether her reaction was consistent with the intention of the child protagonist in the story. These analyses were done separately for the good intentioned/bad intentioned stories since an overall chi-square was not appropriate because of the mixed withinbetween-subject design. For example, if the child in the story intended harm (bad intentions) and subsequently got in trouble with the mother for the act (negative maternal reaction), the mother's reaction is considered consistent with the child's intention (thus, what adults would consider fair). Conversely, if the child was praised by the mother for a bad intended act, this is noted as inconsistent (and what one should consider unfair).

Chi-square analyses for the bad intention stories reveals that there was a significant association between consistency of mother's reaction and the intention of the protagonist, $\chi^{2}(1)=11.27, p<.001$. This seems to represent that fact that, based on the odds ratio, the odds of calling the mother unfair when mother was not consistent was ten times higher in younger children than in older ones. Older children judged the mother to be fair/unfair when her approval/disapproval was consistent with the principle of intentionality. Specifically, $87 \%$ of older children judged the mother to be fair when her reaction to the bad intended protagonist was negative and they judge her as unfair when her reaction was positive to the protagonist in this story. Younger children, in contrast, judged mother who praised the fictive child as fair and the mother who punished the fictive child as unfair regardless of the act.

For the story with a good intention by the protagonist, a similar chi-square analysis was performed to again test whether older and younger children differed in how they determined whether the mother was fair based on whether her reaction was consistent with the good intention of the protagonist or inconsistent with it. There was no association between mother's consistency with the protagonist's good intention in older versus younger children. Although the good intention stories did not show significant results, $\chi^{2}(1)=2.10, p>.05$, this nonsignificant trend may be explained by the fact that the children (even the older children) were divided in their evaluations of fairness for the GI/BO/- story. It is plausible that for that particular story, the children might have acknowledged that being punished for a bad outcome, despite good intentions, was still somehow "fair" because the fictive child was careless. After all, previous research suggests everyone judge acts not just according to ultimate intentions, but also according to other factors such as care taken, etc. (i.e., Nobes et al., 2009; Mulvey, Hitti, Smetana, \& Killen, 2016). It should be noted that, conversely, in the GI/BO/+ story, nearly all of the children regard the mother as fair. Table 1 illustrates these findings. 
Table 1: Child Sense of Fairness by Age, Matched With Maternal Response

\begin{tabular}{|c|c|c|c|c|}
\hline \multirow{2}{*}{$\begin{array}{l}\text { Child } \\
\text { Intention/ } \\
\text { Maternal } \\
\text { Response }\end{array}$} & \multirow[b]{2}{*}{$\begin{array}{c}\text { Child Sense of } \\
\text { Fairness }\end{array}$} & \multicolumn{2}{|c|}{ Child Age } & \multirow[b]{2}{*}{ Total } \\
\hline & & $\begin{array}{c}\text { Older (7-11) } \\
\text { Count (\%) }\end{array}$ & $\begin{array}{c}\text { Younger (3-6) } \\
\text { Count (\%) }\end{array}$ & \\
\hline \multirow{4}{*}{$-1-$} & & Bad intention & & \\
\hline & Fair & $11(100.0 \%)$ & $5(41.7 \%)$ & $16(69.6 \%)$ \\
\hline & Not fair & $0(0.0 \%)$ & $7(58.3 \%)$ & $7(30.4 \%)$ \\
\hline & Total & $11(100.0 \%)$ & $12(100.0 \%)$ & $23(100.0 \%)$ \\
\hline \multirow[t]{3}{*}{$-1+$} & Fair & $3(25.0 \%)$ & $8(38.5 \%)$ & $11(44.0 \%)$ \\
\hline & Not fair & $9(75.0 \%)$ & $5(38.5 \%)$ & $14(56.0 \%)$ \\
\hline & Total & $12(100.0 \%)$ & $13(100.0 \%)$ & $25(100.0 \%)$ \\
\hline \multirow{4}{*}{$+1-$} & & Good intention & & \\
\hline & Fair & $3(42.9 \%)$ & $6(60.0 \%)$ & $9(52.9 \%)$ \\
\hline & Not fair & $4(57.1 \%)$ & $4(40.0 \%)$ & $8(47.1 \%)$ \\
\hline & Total & $7(100.0 \%)$ & $10(100.0 \%)$ & $17(100.0 \%)$ \\
\hline \multirow[t]{3}{*}{$+/+$} & Fair & $15(93.8 \%)$ & $12(80.0 \%)$ & $27(87.1 \%)$ \\
\hline & Not fair & $1(6.3 \%)$ & $3(20.0 \%)$ & $4(12.9 \%)$ \\
\hline & Total & $16(100.0 \%)$ & $15(100.0 \%)$ & $31(100.0 \%)$ \\
\hline
\end{tabular}

Chi-square analysis was also used to evaluate if younger children and older children differ in their use of outcome to judge whether the child protagonist did something good or bad. As expected from Piaget's (1932/1965) earlier findings, results revealed that older children make their judgments about good versus bad based on intention rather than outcome, whereas younger children judge the protagonist to be good or bad by looking at outcome and ignoring intention, $\chi^{2}(1)=5.30, p<.05$.

Chi-square analyses were also employed to examine whether the children used maternal reaction as a guideline in judging the protagonist as good or bad. It is clear that younger children overwhelmingly used the mother's positive or negative response when giving their own good/bad judgment even when the mother's reaction was inconsistent with the intention of the child protagonist $(\mathrm{GI} / \mathrm{BO} /-, \mathrm{BI} / \mathrm{GO} /+), \chi^{2}(1)=10.30, p<.01$. Specifically, if the maternal reaction to the protagonist in the bad intention story was positive, younger children were significantly more likely to judge the child protagonist as having done something good. If the maternal reaction to the protagonist in the good intention story was negative, younger children were significantly more likely to judge the child protagonist as having done something bad. Whereas younger children used the mother's reaction as a compass in making their own judgments of good versus bad, older children did not. As previously shown, older children judged good versus bad based on intention; they did not significantly factor into their implicit rule the maternal response to the child protagonist. Table 2 shows the above findings. 
Table 2: Child Report on Story Child Behavior by Age, Matched With Maternal Response

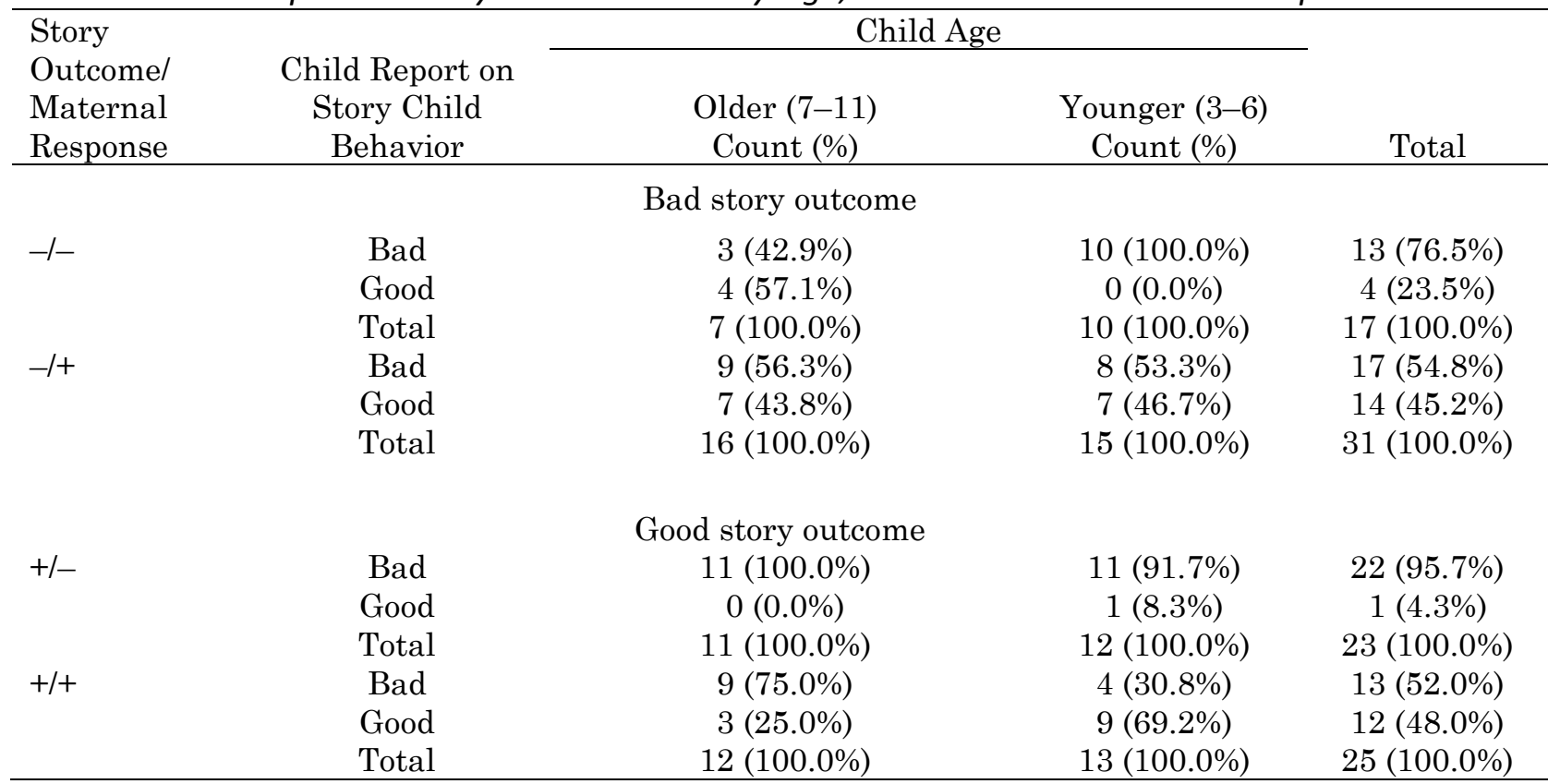

To summarize, the analyses indicated the following significant results: (a) Older children judged the mother to be fair when her reaction (approval/disapproval) matched the child's rather than the outcome of the act (i.e., GI/BO/+, BI/GO/-), while younger children judged maternal fairness on other grounds, fair when mother approved and unfair when she disapproved. (b) Older children judged good versus bad based on intention (not outcome), whereas (c) younger children relied on maternal reaction to a transgression and outcome (not intention) when judging good versus bad. It should be noted that while experimenter influence was possible, the clarity of the response pattern makes this explanation seem highly unlikely.

\section{Discussion}

The results clearly indicate that upon examining the GI/BO/+ story versus GI/BO/- story, when maternal reaction to a GI/BO was negative, younger children all said the protagonist did something "bad" whereas when maternal reaction to the same story was positive, younger children and older children were split on their good/bad judgments. Additionally, older children largely rated the protagonist as "good" for the GI/BO/- story, thus prescribing to the expected focus on intentionality. The fact that not all of the older children made a judgment of good could be a function of the idea of negligence where they may have considered that the bad outcome was somehow foreseeable. It was also found that when maternal reaction is positive for this GI/BO story, the majority of children judged the mother to be fair. However, based on the analyses, the older children judged her to be fair due to consistency between the valence of the intention and of the maternal reaction (positive reaction for good intentions but negative reaction for bad intentions). Younger children did not do this. They may simply have judged a positive maternal reaction to be fair and a negative reaction unfair regardless of the nature of the act. Another way to understand the findings for the younger children is that the fictive mother's reaction was the outcome on which they focused and which determined their judgments of fairness. 
It is clear that when maternal reaction to a bad intention/good outcome was negative, nearly all the children of any age say the protagonist did something bad. When the maternal reaction was positive for the same story, older children still overwhelmingly judged the protagonist as "bad," while younger children tended to change their judgment to "good." Strikingly, all the older children judged the mother's reaction as fair when her reaction was negative (and thus appropriate for a bad intention), while the younger children's judgments were split. The younger children also tended to judge the mother as fair when her reaction was positive (even though, by adult norms, it would be inappropriate for a bad intention act).

The results of this study support Piaget's finding that younger children tend to focus on outcomes when judging the actions of others to be good or bad at least in this parent-child context, whereas older children focus on intention when making moral judgments. More significantly, the results also indicate that for the younger children, maternal reaction when evaluating both good and bad, and maternal fairness and unfairness was judged according to its valence rather than to how it matches the fictive child's intentions. In contrast, older children overwhelmingly judged maternal reaction to be fair only if it appropriately and accurately judged according to the fictive child's intentions in the situation, regardless of the outcome.

To summarize, older children judged the mother in the story to be unfair when she reprimanded the protagonist for a bad outcome, despite good intentions, and most significantly, they even found her to be unfair when she approved the protagonist for a good outcome but with bad intentions. The latter of these findings was so strong, that it was found among all the participants 7 years of age and older. There was a similar pattern for older children when the mother rewarded for a good intention, bad outcome story, but this finding was not obtained when the mother reprimanded the protagonist for a good intention but bad outcome act. It is quite noteworthy that older children found it acceptable, and thus fair, for a mother to reprimand when the intention is bad, even if the outcome is good or benign. It appears that the older, but not younger children used their own moral standard of intentionality as a template by which to judge mother's fairness. This is consistent with Grusec and Goodnow's (1994) general admonition to look to the children's own evaluation of the parent's intervention as a mediator between parenting and children's development.

Overall, the findings demonstrate that younger children do not appear to require maternal reaction to be consistent with actor's intentions when judging what is fair whereas older children do. Additionally, the findings indicate that children over 7 years of age do tend to focus on intention, rather than solely on outcome when making moral judgments as would be expected according to Piaget's conception of heteronomous and autonomous morality. It appears that for older, but not younger, children, maternal reaction to a transgression does not by itself influence their judgments of good or bad. The results demonstrate that older children judge a mother to be fair when her reaction, positive or negative, is consistent with the intentions of the actor in the story rather than with the outcome.

While the present study builds upon the knowledge base of Piaget's theory of moral development as a function of cognitive development, it also adds to the relatively scarce body of research that examines how children both incorporate maternal reaction into their moral judgments and how they evaluate maternal discipline as fair or not fair according to their own moral reasoning. Some limitations of the present study include that the children's judgments were based on hypothetical vignettes and hypothetical mothers. While we assume that such stories are akin to real-life transgressions, we cannot be sure that children would judge fairness in the same way if these were transgression 
encounters that they had personally experienced. Furthermore, this study did not take into account the child's own experience of maternal discipline. It seems plausible to speculate that a child's own experience of parenting may impact their judgments of both right and wrong and maternal fairness. Future research needs to evaluate how children determine further what is fair and not fair and how maternal discipline directly affects such judgment, as well as how the child's judgment of the mother mediates the relationship between maternal discipline and child outcome. It would be particularly interesting to see if a child's own experience of parenting and discipline style has any bearing on how they evaluate maternal fairness in both fictional and real-life stories.

In sum, both parents and researchers seek to navigate how we teach children right from wrong and how their moral judgments both unfold and are influenced. Entwined with an understanding of right and wrong is an inherent sense of what is fair (i.e., Laupa \& Turiel, 1986). Children appear to have a definite opinion of when parental discipline is fair or not fair but this notion clearly changes with age in a standard way.

This study supports research showing that different transgressions are viewed as more or less deserving of punishment and that these evaluations differ as a function of a child's age, as well as their ability to coordinate multiple aspects of the act in question (Jambon \& Smetana, 2014). The present study further suggests that the determinants of children's fairness judgments appear to be potentially affected by a child's own moral reasoning and how it matches the parental reaction to the transgression. These findings have implications for both parents' and researchers' understanding of how children's sense of parental fairness develops and the potential influence of how parental reaction to a transgression encounter may impact both moral understanding and evaluations of fairness. Thus, these findings may have practical significance for parents in how they learn to both explain and discuss discipline choices with children of various developmental levels. For example, parental focus on the child's intentions when reprimanding may encourage both the child's development of the principle of moral intentionality and the child's sense that the parent is being fair. Whereas use of certain types of punishment, which may potentially disregard the moral nature of the act, could both have a deleterious effect on the child's moral reasoning and the parent-child relationship. This research paradigm should be extended to other dimensions of morality; however, intentions are central to morality and therefore provide a good starting place.

\section{References}

Bearison, D. J., \& Isaacs, L. (1975). Production deficiency in children's moral judgments. Developmental Psychology, 11, 732-737.

Castelli, I., Massaro, D., Sanfey, A. G., \& Marchetti, A. (2014). "What is fair for you?" Judgments and decisions about fairness and theory of mind. European Journal of Developmental Psychology, $11,49-62$.

Costanzo, P. R., Coie, J. D., Grumet, J. F., \& Farnill, D. (1973). A reexamination of the effects of intent and consequence on children's moral judgments. Child Development, 44, 154-161.

Gummerum, M., \& Chu, M. T. (2014). Outcomes and intentions in children's, adolescents', and adults' second-and third-party punishment behavior. Cognition, 133, 97-103.

Grusec, J. E., \& Goodnow, J. J. (1994). Impact of parental discipline methods on the child's internalization of values: A reconceptualization of current points of view. Developmental Psychology, 30, 4-19. 
Jambon, M., \& Smetana, J. G. (2014). Moral complexity in middle childhood: Children's evaluations of necessary harm. Developmental Psychology, 50, 22-33.

Kant, I. (1958). Groundwork of the metaphysics of morals (H. J. Paton, Trans.). New York, NY: Harper and Row. (Original work published 1785)

Killen, M., \& Smetana, J. G. (2015). Origins and development of morality. In M. E. Lamb (Ed.), Handbook of child psychology and developmental science, (Vol. 3, 7th edition; pp. 701-749). New York, NY: Wiley-Blackwell.

Konstantareas, M. M., \& Debois, N. (2001). Preschoolers perceptions of the unfairness of maternal disciplinary practices. Child Abuse and Neglect, 25, 473-488.

Laupa, M., \& Turiel, E. (1986). Children's conceptions of adult and peer authority. Child Development, 57, 405-412.

LoBue, V., Nishida, T., Chiong, C., DeLoache, J. S., \& Haidt, J. (2011). When getting something good is bad: Even three-year-olds react to inequality. Social Development, 20, 154-170.

Mulvey, K. L., Hitti, A., Smetana, J. G., \& Killen, M. (2016). Morality, context, and development. In L. Balter \& C. S. Tamis-LeMonda (Eds), Child psychology: A handbook of contemporary issues (3rd edition; pp. 285-303). New York, NY: Psychology Press.

Nobes, G., Panagiotaki, G., \& Pawson, C. (2009). The influence of negligence, intention, and outcome on children's moral judgments. Journal of Experimental Child Psychology, 104, 382-397.

Piaget, J. (1965). The moral judgment of the child. New York, NY: Free Press. (Original work published 1932)

Shaw, A., DeSciolo, P., \& Olson, K. R. (2012). Fairness versus favoritism in children. Evolution and Human Behavior, 33, 736-745.

Smetana, J. G. (1999). The role of parents in moral development: A social domain analysis. Journal of Moral Education, 28, 311-321.

Smetana, J. G., Jambon, M., \& Ball, C. (2014). The social domain approach to children's moral and social judgments. In M. Killen \& J. G. Smetana (Eds), Handbook of moral development (2nd edition). New York, NY: Psychology Press.

Stone, C. R., \& Selman, R. L. (1982). A structural approach to research in the development of interpersonal behavior among grade school children. In K. H. Rubin \& H. S. Ross (Eds), Peer relationships and social skills in childhood. New York, NY: Springer.

Suls, J., Gutkin, D., \& Kalle, R. J. (1979). The role of intentions, damage, and social consequences in the moral judgments of children. Child Development, 50, 874-877. 
The Journal of Social, Behavioral, and Health Sciences is an open-access, peer-reviewed, online interdisciplinary journal focusing on research findings that address contemporary national and international issues. Its objectives are to (a) encourage dialogue between scholars and practitioners in the social, behavioral, and health sciences that fosters the integration of research with practice; (b) promote innovative models of interdisciplinary collaboration among the social, behavioral, and health sciences that address complex social problems; and (c) inform the relationship between practice and research in the social, behavioral, and health sciences.

Walden University Publishing: http://www.publishing.waldenu.edu 